\title{
Digital Nativity, Computer Self-Efficacy, and Technology Adoption: A Study Among University Faculties in China
}

\author{
Chen Zhao and Lei Zhao* \\ College of Science and Information Science, Qingdao Agricultural University, Qingdao, China
}

Technology acceptance and usage become obligatory for people when their work modes change as a result of an unexpected but irresistible force. This is especially true for teachers who are reluctant technology adopters compared with their students. During the COVID-19 pandemic, the Chinese government issued national policies to enforce online teaching and learning. As the success of online teaching largely depends on university faculties' readiness and intentions, how they perceive and practice technology adoption becomes an issue that warrants in-depth research. Unlike their students who grow up with technology and can be seen as digital natives, university faculties may lack competence in using technology, whether to teach or do other tasks. Previous studies on faculties' technology adoption were all conducted in situations where they made volitional decisions to use technology, but their mandatory technology use received scant

OPEN ACCESS

Edited by:

Fang Huang,

Qingdao University, China

Reviewed by:

LI Sun,

Xiamen University, China Jinbo He,

The Chinese University of Hong Kong, China

*Correspondence: Lei Zhao

154372732@qq.com

Specialty section:

This article was submitted to Educational Psychology, a section of the journal Frontiers in Psychology

Received: 23 July 2021 Accepted: 24 August 2021 Published: 21 September 2021

Citation:

Zhao C and Zhao L (2021) Digital Nativity, Computer Self-Efficacy, and Technology Adoption: A Study Among

University Faculties in China.

Front. Psychol. 12:746292.

doi: 10.3389/fpsyg.2021.746292 attention. In addition, although studies suggested that teachers demonstrated features of digital natives, it remains unknown whether or to what extent their digital nativity correlates with technology intentions. To address these research gaps, the current study examined Chinese university faculties' intentions to use technology for online teaching by incorporating digital nativity and computer self-efficacy as key determinants into technology acceptance variables. Results suggested that digital nativity was a key factor that affected university faculties' online teaching, as evidenced by the fact that $67 \%$ of the variance could be explained by perceived usefulness, attitudes and digital nativity. In addition, it was also found that computer efficacy significantly influenced perceived ease of use.

Keywords: technology acceptance, digital nativity, computer self-efficacy, university faculties, China

\section{INTRODUCTION}

Digitalization encourages people of different professions to improve their job performance with information and communication technologies. With COVID-19 sweeping the world, technology integration in education has greatly aroused educational stakeholders' attention and discussion. To ensured continued teaching and learning, university faculties resorted to various synchronous online teaching tools such as Zoom, Microsoft Teams, and Tencent Classroom (Huang et al., 2021b). Although this drastic teaching-mode shift facilitates teachers' pedagogical design thinking on technology (Tsai and Chai, 2012), it brings great cognitive, emotional, and technical challenges to those who are not familiar with technology-enhanced teaching. It is, therefore, necessary to examine university faculties' perceptions of technology adoption in teaching.

Ever since Prensky (2001) made the distinction between digital natives and digital immigrants based on thinking and behavior patterns, scholars have conducted research to assess technology 
users' digital nativity (Çoklar et al., 2017; Huang et al., 2021c). Although it remains arguable whether age is one of the key criteria in defining digital natives (Kennedy et al., 2008), researchers (e.g., Teo, 2013) adopted Prensky (2001)'s definition to develop the Digital Nativity Assessment Scale to assess digital nativity. Building on Prensky's interpretation of features of digital natives, namely, grow up with technology, comfortable with multi-tasking, reliant on graphics for communication and thrive on instant gratification and rewards, existing studies on digital natives and their technology adoption mostly focused on student cohort (e.g., Bennett and Maton, 2010; Teo, 2013; Chen et al., 2016; Tran et al., 2020), with few studies examining adult users' digital nativity. To address this research gap, studies conducted in a higher education context suggested that university teachers also demonstrated features of digital natives (Smith et al., 2020; Huang et al., 2021c), which empirically supported scholars' doubt about defining digital nativity by age. Despite these efforts, it remains unknown whether and to what extent digital nativity is related to university teachers' technology adoption.

As the first country enforcing the COVID-19 pandemic lockdown, China was among the first to move from traditional classroom teaching to full online teaching under the initiative of "Suspending Classes without Stopping Learning" (Huang et al., 2021b). This drastic shift may bring about changes in university faculties' perceptions and present significant challenges for teachers' adaption to online teaching. Therefore, it is necessary to investigate their online teaching during the pandemic lockdown. The research question of the current study is: To what extent the research model explains university faculties' online teaching during the pandemic? To answer the research question, the study used a survey to inquire into university faculties' responses to technology adoption.

\section{MODEL DEVELOPMENT}

\section{Technology Acceptance Model}

Widely used by scholars to unpack users' intentions of technology use internationally, the technology acceptance model (TAM) proposed by Davis (1989) is suggested as one of the most valid theories in predicting users' technology acceptance (King and He, 2006; Al-Emran et al., 2018; Granić and Marangunić, 2019; Huang et al., 2021a,b). In the TAM, there are two main variables that explain users' intentions: Perceived usefulness (PU) and perceived ease of use (PEU) (Davis, 1989). PU refers to one's belief that using technology helps improve work performance and efficiency (Teo, 2009), while PEU indicates a belief about using technologies without any effort. According to Davis (1989), PEU influences PU and both of them are associated with attitudes (ATU) which measures one's fondness of technology. Behavior intention (BI) measures the degree of one's aspiration or willingness to use technology and is influenced by both ATU and PU (Davis, 1989; Teo, 2009). In previous studies contextualized in Chinese higher educational settings, Teo et al. (2018) accepted the TAM as valid in explaining Chinese English teachers' intentions to use technology. Those discussions gave rise to the following hypotheses.

H1: PU is significantly related to ATU.

$\mathrm{H} 2$ : PU is significantly related to BI.
H3: PEU is significantly related to PU.

H4: PEU is significantly related to ATU.

H5: ATU is significantly related to BI.

\section{Extended Variables: Computer Self-Efficacy and Digital Natives}

An extended variable in this study is computer self-efficacy (CSE), which measures the extent to which an individual believes that he or she has the ability to perform online teaching with technology (Compeau and Higgins, 1995). CSE derives from Bandura (1977)'s notion of self-efficacy that gauges the extent to which one perceives that he or she has the ability to organize, execute actions and achieve specific goals. In technology acceptance studies, researchers found that CSE played a significant role in influencing users' perceived ease of use (Teo et al., 2018; Bai et al., 2021; Huang and Teo, 2021). In this study, we included CSE as an extended variable because we believe individuals with a high level of CSE may not easily feel anxious or frustrated when they face unexpected challenges, such as the emergent shift to online teaching as a result of COVID-19 in particular. In addition, they are more likely to overcome technological difficulties (Compeau and Higgins, 1995) and thus perceive online teaching as a nottoo-difficult or even a handy task. In light of this revelation, another hypothesis arises.

H6: CSE is significantly associated with PEU.

Another important variable included in this study is digital nativity (DN) which characterizes new generation's technology preference and behavior. In 2001, Prensky proposed that digital natives were a new generation of learners who entered higher education, and that they were different from digital immigrants because they were naturally digitally literate and inherently proficient users of technology. Prensky refers to digital natives as those who grow up with technology, demonstrate features of parallel processing and multitasking, and usually rely on technology to perform diverse tasks, such as learning and interpersonal communication. Unlike digital immigrants who are not used to using technology to perform tasks, digital natives prefer using graphics to express ideas and expect prompt responses (Prensky, 2001; Teo, 2013). Although Prensky considered people who are born after the 1980s as typical digital natives, scholars argued that digital natives were not an identifiable generation solely defined by age (Bennett and Maton, 2010; Huang et al., 2021c). Many people who did not grow up in a pervasive ICT environment also demonstrate features of digital natives if they become familiar with ICT through constant use of technology (Ransdell et al., 2011). This argument was validated by Huang et al. (2021c)'s study of English teachers in a Chinese higher educational context. To further unpack its influence on faculty members' intentions to adopt online teaching during the pandemic, the current study examined their digital nativity (DN) and its impact on their online teaching intentions by associating DN with the main variables of the TAM (PU, PEU, ATU, and BI) as well as the CSE.

To achieve this goal, we used the Digital Navies Assessment Scale (DNAS) developed by Teo (2013) to measure university faculties' digital nativity, given that the DNAS has been validated among teachers in diverse cultural contexts (e.g., Teo et al., 2016; Huang et al., 2021c). The DNAS consists of four dimensions: 


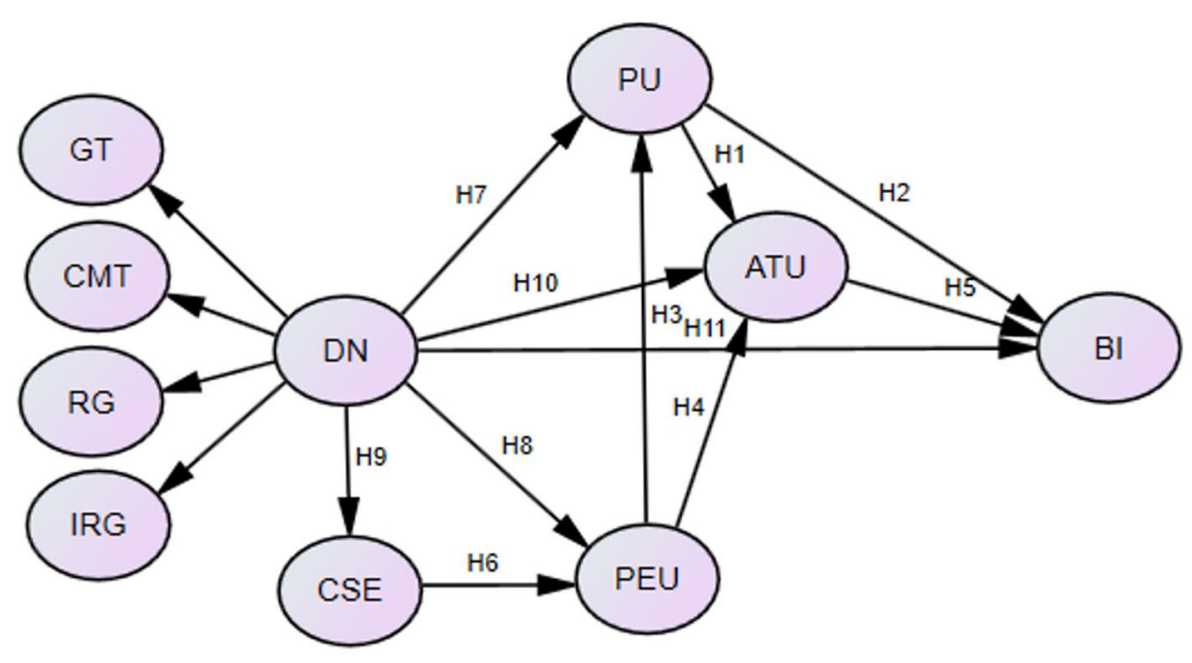

FIGURE 1 | The research model. PU, perceived usefulness; PEU, perceived ease of use; ATU, attitude; BI, behavioral intention; CSE, computer self-efficacy; DN, digital nativity; GT, grow up with technology; CMT, comfortable with multi-tasking; RG, reliant on graphics for communication; IRG, thrive on instant gratification and rewards.

grow up with technology (GT), comfortable with multitasking (CMT), reliant on graphics for communication (RG), and thrive on instant gratification and rewards (IRG), thus giving rise to five additional hypotheses whose interactions with other hypotheses form the research model of the current study (as shown Figure 1).

H7: DN is significantly associated with PU.

H8: DN is significantly associated with PEU.

H9: DN is significantly associated with CSE.

H10: DN is significantly associated with ATU.

$\mathrm{H} 11$ : DN is significantly associated with BI.

\section{MATERIALS AND METHODS}

\section{Participants and Data Collection}

This study was conducted in the Spring of 2020. Participants are 502 faculties from 30 universities in China. Approached by our contacts in Chinese universities, they were invited to fill in a survey questionnaire designed for the study. Researchers in this study designed the research questionnaire, converted it into a survey using Wenjuanxing, a widely used online survey tool in China, and distributed it with WetChat, a popular social media app in China.

Before the study, participants were informed of the voluntariness of their participation in the study. They each spent about $15 \mathrm{~min}$ filling out the questionnaires. After data collection, responses were carefully checked to ensure the completeness. Among the participants, $77.9 \%$ were females and $22.1 \%$ were males. Their ages ranged from 23 to 59, with the mean age being $37.6(\mathrm{SD}=6.77)$. The mean length of their university work experience was 13 years $(\mathrm{SD}=7.44)$, and the mean year of their technology use in teaching was $9.33(\mathrm{SD}=5.30)$.

\section{Instruments}

The questionnaire designed for the research consists of two sections. Section One includes questions to obtain the demographic information of the participants, such as their age, gender, and technology use experience. Section Two comprises a series of items underlying constructs adapted from various sources in which the validity and reliability of the constructs were suggested. Those constructs are: Computer self-efficacy (Compeau and Higgins, 1995; Teo et al., 2018); perceived usefulness, perceived ease of use, attitudes, behavioral intention derived from the technology acceptance model (Davis, 1989); and the Digital Nativity Assessment Scale (DNAS, Teo, 2013). The DNAS includes four sub-constructs: grow up with technology, comfortable with multitasking, reliant on graphics for communication, thrive on instant gratification and rewards. All the items were tested by the 7-point Likert Scale from 1 to 7 (1 stands for "Completely Disagree," 7 stands for "Completely Agree").

\section{Data Analysis}

To examine the hypothesized relationships, structural equation modeling (SEM) with the maximum likelihood as the method for estimating parameters was conducted using AMOS 24.0. SEM was chosen as the main data analysis technique because it enabled us to see the relationships among the proposed constructs simultaneously. As suggested by Anderson and Gerbing (1988), we performed a two-step analysis (the measurement model and the structural model). To be specific, the confirmatory factor analysis of the measurement model was set to describe the fit between the observed indicators (items) and the underlying constructs in the sample data, while the structural model was tasked with examining the significance of the hypotheses.

\section{RESULTS}

\section{Descriptive Statistics}

As shown by the descriptive statistics for the constructs in Table 1, faculty members generally responded positively to online teaching, with the mean values of the constructs varying from 
TABLE 1 | Information of the constructs.

\begin{tabular}{lccccc}
\hline Constructs & N of items & Minimum & Maximum & Mean & SD \\
\hline Perceived usefulness & 6 & 1.00 & 7.00 & 5.84 & 0.87 \\
Perceived ease of use & 4 & 1.60 & 7.00 & 4.92 & 0.95 \\
Attitudes & 5 & 1.80 & 7.00 & 5.45 & 0.90 \\
Computer self-efficacy & 7 & 1.86 & 7.00 & 5.16 & 0.75 \\
$\begin{array}{l}\text { Behavioral intention } \\
\text { Grow up with technology }\end{array}$ & 5 & 2.00 & 7.00 & 5.69 & 0.90 \\
Comfortable with & 3 & 1.00 & 7.00 & 5.73 & 0.98 \\
multi-tasking & 5 & 1.67 & 7.00 & 5.05 & 1.11 \\
$\begin{array}{l}\text { Reliant on graphics for } \\
\text { communication }\end{array}$ & 5 & 1.00 & 7.00 & 4.53 & 1.04 \\
$\begin{array}{l}\text { Thrive on instant gratification } \\
\text { and rewards }\end{array}$ & 4 & 2.00 & 7.00 & 5.32 & 0.89 \\
\hline
\end{tabular}

4.53 to 5.73. In addition, kurtosis and skewness were assessed for univariate normality by applying the criteria of $|3|$ and $|8|$ (Kline, 2011). Skewness and Kurtosis ranged from -0.40 to 3.50 and from -1.04 to 0.155 , respectively, indicating that the data demonstrated a normal distribution.

\section{Testing the Measurement Model}

The analysis of the measurement model shows the factor loadings of the underlying constructs and the model fit between the observed indicators and the underlying constructs. The confirmatory factor analysis (CFA) with the use of maximum likelihood estimation was performed. The value of Mardia's coefficient was 638.307, much lower than the recommended value of 2024 which is calculated as $p(p+2)$, where $p$ indicates the total number of observed items. This suggested the multivariate normality was achieved and thus adequate for the confirmatory factor analysis (Raykov and Marcoulides, 2011). The factor loadings of the constructs are shown in Table 2. Most item loadings were near or above 0.6 , indicating the significance of these items to their underlying constructs (Hair et al., 2010). To test the reliability and convergent validity of the constructs, composite reliability (CR) and average variance extraction (AVE) were used based on the acceptable level of 0.70 (Gefen et al., 2000) and 0.50 (Fornell and Larcker, 1981), respectively. Table 2 indicates that CRs and AVEs met the above criteria, except for the AVE of CSE, suggesting that the items used in this study generally possess adequate psychometric properties. Besides, the model fit indices used in this study are the ratio of the minimum fit function to its degree of freedom $\left(\chi^{2} / \mathrm{df}\right)$, with a value lower than 3.0 to be considered desirable (Carmines and McIver, 1981); the Comparative Fit Index (CFI) and Tucker-Lewis Index (TLI), with values $>0.90$ indicating a good fit (Hair et al., 2010); the Root-Mean-Square Error of Approximation (RMSEA) and the Standardized Root Mean Square Residual (SRMR), with values lower than 0.08 indicating a good model fit (Hair et al., 2010). Based on these criteria, results of this study indicated that the measurement model had achieved a good model fit $\left(\chi^{2} / \mathrm{df}=\right.$ $2.248, \mathrm{TLI}=0.916, \mathrm{CFI}=0.923, \mathrm{SRMR}=0.0579$, and $\mathrm{RMSEA}=$ $0.050[0.047,0.053])$.
TABLE 2 | Factor loadings of the constructs.

\begin{tabular}{|c|c|c|c|c|}
\hline Factors & Indicators & Loadings & CR & AVE \\
\hline \multirow[t]{6}{*}{ Perceived usefulness (PU) } & PU1 & 0.778 & 0.897 & 0.593 \\
\hline & PU2 & 0.796 & & \\
\hline & PU3 & 0.71 & & \\
\hline & PU4 & 0.773 & & \\
\hline & PU5 & 0.688 & & \\
\hline & PU6 & 0.864 & & \\
\hline \multirow[t]{4}{*}{ Perceived ease of use (PEU) } & PEU1 & 0.717 & 0.872 & 0.631 \\
\hline & PEU2 & 0.785 & & \\
\hline & PEU3 & 0.871 & & \\
\hline & PEU4 & 0.796 & & \\
\hline \multirow[t]{5}{*}{ Attitude (ATU) } & ATU1 & 0.822 & 0.874 & 0.582 \\
\hline & ATU2 & 0.792 & & \\
\hline & ATU3 & 0.637 & & \\
\hline & ATU4 & 0.794 & & \\
\hline & ATU5 & 0.756 & & \\
\hline \multirow[t]{5}{*}{ Behavioral intention (BI) } & $\mathrm{Bl} 1$ & 0.799 & 0.923 & 0.708 \\
\hline & $\mathrm{Bl} 2$ & 0.896 & & \\
\hline & $\mathrm{BI} 3$ & 0.926 & & \\
\hline & $\mathrm{B} 14$ & 0.744 & & \\
\hline & $\mathrm{B} 15$ & 0.83 & & \\
\hline \multirow[t]{3}{*}{ Grow up with technology (GT) } & GT1 & 0.816 & 0.879 & 0.708 \\
\hline & GT2 & 0.897 & & \\
\hline & GT3 & 0.808 & & \\
\hline \multirow{5}{*}{$\begin{array}{l}\text { Comfortable with multitasking } \\
(\mathrm{CMT})\end{array}$} & CMT1 & 0.66 & 0.874 & 0.583 \\
\hline & СMT2 & 0.723 & & \\
\hline & СMT3 & 0.816 & & \\
\hline & CMT4 & 0.793 & & \\
\hline & CMT5 & 0.815 & & \\
\hline \multirow{5}{*}{$\begin{array}{l}\text { Reliant on graphics for } \\
\text { communication (RG) }\end{array}$} & RG1 & 0.723 & 0.874 & 0.583 \\
\hline & RG2 & 0.822 & & \\
\hline & RG3 & 0.796 & & \\
\hline & RG4 & 0.828 & & \\
\hline & RG5 & 0.629 & & \\
\hline \multirow{4}{*}{$\begin{array}{l}\text { Thrive on instant gratification and } \\
\text { rewards (IRG) }\end{array}$} & IGR1 & 0.779 & 0.807 & 0.513 \\
\hline & IGR2 & 0.719 & & \\
\hline & IGR3 & 0.746 & & \\
\hline & IGR4 & 0.61 & & \\
\hline \multirow[t]{7}{*}{ Computer self-efficacy (CSE) } & CSE1 & 0.596 & 0.864 & 0.477 \\
\hline & CSE2 & 0.721 & & \\
\hline & CSE3 & 0.719 & & \\
\hline & CSE4 & 0.56 & & \\
\hline & CSE5 & 0.75 & & \\
\hline & CSE6 & 0.752 & & \\
\hline & CSE7 & 0.713 & & \\
\hline
\end{tabular}

CR, composite reliability; AVE, average variance extracted.

\section{Testing the Structural Model}

After ensuring the reliability and the validity of the measurement model, we further tested the structural model to examine 
hypothesized relationships in the research model, as well as the percentage of the variance predicted. The structural model achieved a good model fit $\left(\chi^{2} / \mathrm{df}=2.382\right.$, CFI $=0.913$, TLI $=0.907$, RMSEA $=0.053[0.050,0.055]$, SRMR $=0.0728)$. Table 3 shows the results of the hypotheses proposed in the research model.

The proposed research model explained $67 \%$ of university faculties' technology adoption intentions. Variances explained for ATU, PEU, CSE, and PU are 69, 25, 46, and 43\%, respectively. Besides, all the four sub-constructs measuring digital nativity achieved significance with their path coefficients being 0.767 (grow up with technology, GT), 0.443 (comfortable with multitasking, CMT), 0.390 (reliant on graphics for communication, RG) and 0.761 (thrive on instant gratification and rewards, IRG).

As for university faculties' digital nativity, results indicated that they demonstrated features of digital natives with their mean values all above 4 (Table 1). In addition, their digital nativity was significantly associated with perceived usefulness (H7), perceived ease of use (H8), computer self-efficacy (H9), attitudes (H10), and behavioral intentions (H11).

Perceived usefulness and perceived ease of use were both related to faculties' attitudes toward technology use ( $\mathrm{H} 1$ and $\mathrm{H} 4)$, which further impacts their behavioral intention (H5). However, unlike the original technology acceptance model (Davis, 1989), the relationships between perceived usefulness and behavioral intentions (H2) and between perceived ease of use and perceived usefulness (H3) were not significant in this study. Based on the results, cultural and contextual reasons were discussed to support the results.

\section{DISCUSSION}

The results of this study evidence the validity of the TAM to predict teachers' intentions to use technology (Teo et al., 2018; Huang and Teo, 2021), as well as the important role digital nativity played in technology adoption of university faculties, which highlights the importance of incorporating constructs like digital nativity to examine users' technology adoption. This is

TABLE 3 | Results of the hypotheses.

\begin{tabular}{llcl}
\hline Hypotheses & Paths & Path coefficients & Results \\
\hline $\mathrm{H} 1$ & $\mathrm{PU} \rightarrow \mathrm{ATU}$ & $0.529^{\star \star \star}$ & Supported \\
$\mathrm{H} 2$ & $\mathrm{PU} \rightarrow \mathrm{BI}$ & 0.042 & Not supported \\
$\mathrm{H} 3$ & $\mathrm{PEU} \rightarrow \mathrm{PU}$ & 0.07 & Not supported \\
$\mathrm{H} 4$ & $\mathrm{PEU} \rightarrow \mathrm{ATU}$ & $0.243^{\star * *}$ & Supported \\
$\mathrm{H} 5$ & $\mathrm{ATU} \rightarrow \mathrm{BI}$ & $0.291^{\star \star *}$ & Supported \\
$\mathrm{H} 6$ & $\mathrm{CSE} \rightarrow \mathrm{PEU}$ & $0.377^{\star \star \star}$ & Supported \\
$\mathrm{H} 7$ & $0.620^{\star \star *}$ & Supported \\
$\mathrm{H} 8$ & $\mathrm{DN} \rightarrow \mathrm{PU}$ & $0.159^{\star}$ & Supported \\
$\mathrm{H} 9$ & $\mathrm{DN} \rightarrow \mathrm{PEU}$ & $0.677^{\star \star *}$ & Supported \\
$\mathrm{H} 10$ & $\mathrm{DN} \rightarrow \mathrm{CSE}$ & $0.240^{\star \star *}$ & Supported \\
$\mathrm{H} 11$ & $\mathrm{DN} \rightarrow \mathrm{ATU}$ & $0.558^{\star \star \star}$ & Supported \\
\hline
\end{tabular}

${ }^{* \star \star} p<0.001 ;{ }^{*} p<0.01$. especially rationale since many university faculties are digital immigrants and they need to pick up technology skills to cope with job requirements in the digital age. Overall, the research model is able to explain $67 \%$ of BI variance mainly through digital nativity, perceived usefulness and attitudes. Additionally, the research model explains high percentages of the variances of the three core variables from the TAM, namely, $69 \%$ of the variance of ATU, $43 \%$ of PU, and $25 \%$ of PEU.

The hypotheses of the research model are mostly supported. Consistent with the TAM and previous studies, perceived usefulness is related to university faculties' attitudes toward online teaching (Davis, 1989; Huang et al., 2021b; Khlaisanga et al., 2021), which further explains their intentions to adopt online teaching (Sánchez-Prieto et al., 2019). This indicated that when university faculties believe using technology is useful, such as enabling them to conduct teaching and administrative tasks even at the epidemic quarantine, they would form an opposite attitude toward technology use and this feeling directly leads to their technology adoption intentions. Besides perceived usefulness, perceived ease of use is also associated with attitudes, indicating that when university faculties perceived online teaching as a useful and handy task, they would be more likely to be fond of online teaching (Davis, 1989; Teo and Huang, 2019; Khlaisanga et al., 2021). As one of the key factors that examine individuals' self-perceived ability, computer self-efficacy is suggested to relate to university faculties' perceived ease of use, indicating that when they believe they have a sufficient ability to teach online, they would not consider the task as difficult or laborious (Venkatesh and Bala, 2010; Dong et al., 2020). The supported relationship between computer self-efficacy and perceived ease of use is reasonable because self-efficacy measures the degree to which one believes he or she can perform a certain task. For university faculties, when they believe they have sufficient abilities to perform tasks by using technology, such as the emergency remote teaching, they would be very likely to perceive online teaching as an easy task. For those with low computer self-efficacy, online teaching may bring anxiety or confusion to them, and this psychological mindset would impede their intentions to teach online.

As an important annectant proposed in the study, digital nativity is significantly related to PU, PEU, CSE, ATU, and BI, demonstrating its power of predicting university faculties' online teaching adoption. As previous studies suggested (Huang et al., 2019), university teachers demonstrated features of digital natives although many of them were born before the 1980s. However, the presence of such features does not necessarily mean that they have acquired necessary professional skills to fulfill their teaching and administrative tasks, especially with respect to the ability to use technology for such tasks. It is reasonable to believe that when university faculties consider they have grasped necessary technological skills and can act as digital natives, they would think using technology is useful and easy, consider themselves as competent in these skills, form a positive attitude toward technology integration, and ultimately be more likely to engage in technology-enabled teaching.

Inconsistent with the TAM, the relationship between PU and $\mathrm{BI}$ did not achieve significance in this study. Since Chinese people 
often hold collectivist values which strengthen group interests and conformity in thinking and behavior (Hofstede, 2008; Huang et al., 2019), their behaviors are greatly influenced by higher authorities. During the pandemic, Chinese people's collectivism was increasingly strengthened due to the Chinese government's fast and effective response to the pandemic. Therefore, university faculties' decision making may be more likely to be influenced by policy requirement as suggested by Huang and Teo (2021). In addition, the fact that perceived ease of use was not significantly related to perceived usefulness calls for further consideration of antecedents of perceived usefulness by considering cultural and contextual features.

\section{Limitations and Future Study}

This study has some limitations. First, this study used online survey due to the impact of the pandemic. Compared with the traditional paper-and-pencil surveys that provide higher response rates, online survey would not receive a high response rate given the fact that some potential participants are lack of willingness to participate in online survey (Lefever et al., 2007). Second, participants might respond to research questions in a socially desirable direction instead of expressing their true feelings (Richman et al., 1999). Thirdly, during the pandemic, many university faculties were busy with online teaching, compared with the large population in China, the sample size of the study is relatively not big enough and thus, lowered the generalizability of the study results. Therefore, further studies are suggested to diversify data collection methods, increase sample size, involve teachers in diverse subjects to achieve greater generalizability regarding faculties' online teaching. Fourth, the cross-sectional design is also the research limitations and further study would consider diverse research design such as experimental study to unpack causal relationships among the variables. Finally, factors such as age and gender were not examined in the current study and further study is necessary to unpack their influences on technology acceptance.

\section{CONCLUSION}

Contextualized in Chinese higher institutional context, this study investigated university faculties' digital nativity and its association with their online teaching intentions during the COVID-19 pandemic. Based on the results of the study, university faculties demonstrated features of digital nativity,

which is related to the computer self-efficacy and the main factors proposed in the original technology acceptance model. This indicates scholars should revisit the notion of digital natives and include it in considering technology users' intentions to use

\section{REFERENCES}

Al-Emran, M., Mezhuyev, V., and Kamaludin, A. (2018). Technology acceptance model in M-learning context: a systematic review. Comput Educ. 125, 389-412. doi: 10.1016/j.compedu.2018.06.008

Anderson, J. C., and Gerbing, D. W. (1988). Structural equation modeling in practice: a review and recommended two-step approach. Psychol. Bull. 103, 411-423. doi: 10.1037/0033-2909.103.3.411 technology. Results also provide suggestions for both administers of teacher training programs and policy makers to improve teacher professional development, such as the improvement in technical support, and provision of technology training.

\section{DATA AVAILABILITY STATEMENT}

The raw data supporting the conclusions of this article will be made available by the authors, without undue reservation.

\section{ETHICS STATEMENT}

Ethical review and approval was not required for the study on human participants in accordance with the institutional requirements. The participants voluntarily participated in this study and provided their informed consent to participate in this study.

\section{AUTHOR'S NOTE}

Contextualized in Chinese universities, this study contributed to people's understanding of technology acceptance theories by unpacking faculties' digital nativity and its association with computer self-efficacy as well as their technology adoption during the COVID-19 pandemic. Results provided evidence to support the presence of factors that impact faculties' technology adoption during the pandemic. Taking account of those factors and their influences, policy makers, and university administrators can make informed decisions on technologyrelated issues accordingly.

\section{AUTHOR CONTRIBUTIONS}

CZ: conceptualize, data analysis, and writing. LZ: supervision and revision. Both authors contributed to the article and approved the submitted version.

\section{FUNDING}

This study was supported by the project, Exploring and practicing curriculum reform integrating ideological teaching based on the All Three Education Framework (Grant no.: M2020013).

\section{ACKNOWLEDGMENTS}

The authors would like to express gratitude to all the participants in the study.

Bai, B., Wang, J., and Chai, C. S. (2021). Understanding Hong Kong primary school English teachers' continuance intention to teach with ICT. Comput. Assist. Lang. Learn. 34, 528-552. doi: 10.1080/09588221.2019.1627459

Bandura, A. (1977). Self-efficacy: toward a unifying theory of behavioral change. Psychol. Rev. 84:191.

Bennett, S., and Maton, K. (2010). Beyond the 'digital natives' debate: towards a more nuanced understanding of students' technology experiences. J. Comput. Assist. Learn. 26, 321-331. doi: 10.1111/j.1365-2729.2010.00360.x 
Carmines, E., and McIver, J. (1981). Analyzing Models With Unobserved Variables, Social Measurement: Current Issues. Beverly Hills, CA: Sage.

Chen, P. H., Teo, T., and Zhou, M. (2016). Relationships between digital nativity, value orientation, and motivational interference among college students. Learn. Individ. Differ. 50, 49-55. doi: 10.1016/j.lindif.2016.06.017

Çoklar, A. N., Yaman, N. D., and Yurdakul, I. K. (2017). Information literacy and digital nativity as determinants of online information search strategies. Comput. Hum. Behav. 70, 1-9. doi: 10.1016/j.chb.2016.12.050

Compeau, D. R., and Higgins, C. A. (1995). Computer self-efficacy: development of a measure and initial test. MIS Q. 19, 189-211. doi: 10.2307/249688

Davis, F. D. (1989). Perceived usefulness, perceived ease of use, and user acceptance of information technology. MIS Q. 13, 319-340. doi: 10.2307/249008

Dong, Y., Xu, C., Chai, C. S., and Zhai, X. (2020). Exploring the structural relationship among teachers' technostress, technological pedagogical content knowledge (TPACK), computer self-efficacy and school support. Asia Pac. Educ. Res. 29, 147-157. doi: 10.1007/s40299-019-00461-5

Fornell, C., and Larcker, D. F. (1981). Evaluating structural equation models with unobservable variables and measurement error. J. Market. Res. 18, 39-50. doi: $10.1177 / 002224378101800104$

Gefen, D., Straub, D., and Boudreau, M. C. (2000). Structural equation modeling and regression: guidelines for research practice. Commun. Assoc. Inf. Syst. 4:7. doi: 10.17705/1CAIS.00407

Granić, A., and Marangunić, N. (2019). Technology acceptance model in educational context: a systematic literature review. Br. J. Educ. Technol. 50, 2572-2593. doi: 10.1111/bjet.12864

Hair, J. F. Jr., Black, W. C., Babin, B. J., and Anderson, R. E. (2010). Multivariate Data Analysis, 7th Edn. New York, NY: Prentice Hall.

Hofstede, G. (2008). Culture's Consequences: Comparing Values, Behaviors, Institutions and Organizations Across Nations, 2nd Edn. Shanghai: Shanghai Foreign Language Education Press.

Huang, F., Sánchez-Prieto, J. C., Teo, T., García-Peñalvo, F. J., OlmosMigueláñez, S., and Zhao, C. (2021a). A cross-cultural study on the influence of cultural values and teacher beliefs on university teachers' information and communications technology acceptance. Educ. Technol. Res. Dev. 69, 1271-1297. doi: 10.1007/s11423-021-09941-2

Huang, F., Teo, T., and Guo, J. (2021b). Understanding English teachers' non-volitional use of online teaching: a Chinese study. System 101:102574. doi: $10.1016 /$ j.system.2021.102574

Huang, F., Teo, T., and He, J. (2021c). Digital nativity of university teachers in China: factor structure and measurement invariance of the Digital Native Assessment Scale (DNAS). Interact. Learn. Environ. 29, 385-399. doi: $10.1080 / 10494820.2019 .1570278$

Huang, F., and Teo, T. (2021). Examining the role of technology-related policy and constructivist teaching belief on English teachers' technology acceptance: a study in Chinese universities. Br. J. Educ. Technol. 52, 441-460. doi: 10.1111/bjet.13027

Huang, F., Teo, T., Sánchez-Prieto, J. C., García-Peñalvo, F. J., and OlmosMigueláñez, S. (2019). Cultural values and technology adoption: a model comparison with university teachers from China and Spain. Comput. Educ. 133, 69-81. doi: 10.1016/j.compedu.2019.01.012

Kennedy, G. E., Judd, T. S., Churchward, A., Gray, K., and Krause, K. L. (2008). First year students' experiences with technology: are they really digital natives? Aust. J. Educ. Technol. 24, 108-122. doi: 10.14742/ajet.1233

Khlaisanga, J., Teo, T., and Huang, F. (2021). Acceptance of a flipped smart application for learning: a study among Thai university students. Interact. Learn. Environ. 29, 772-789. doi: 10.1080/10494820.2019.1612447

King, W. R., and He, J. (2006). A meta-analysis of the technology acceptance model. Inf. Manag. 43, 740-755. doi: 10.1016/j.im.2006.05.003

Kline, R. B. (2011). Principles and Practice of Structural Equation Modeling, 3rd $E d n$. New York, NY: Guilford Press.

Lefever, S., Dal, M., and Matthíasdóttir, Á. (2007). Online data collection in academic research: advantages and limitations. Br. J. Educ. Technol. 38, 574-582. doi: 10.1111/j.1467-8535.2006.00638.x
Prensky, M. (2001). Digital natives, digital immigrants Part 1. On Horizon 9, 1-6. doi: 10.1108/10748120110424816

Ransdell, S., Kent, B., Gaillard-Kenney, S., and Long, J. (2011). Digital immigrants fare better than digital natives due to social reliance. Br. J. Educ. Technol. 42, 931-938.

Raykov, T., and Marcoulides, G. A. (2011). Introduction to Psychometric Theory. London: Routledge.

Richman, W. L., Kiesler, S., Weisband, S., and Drasgow, F. (1999). A meta-analytic study of social desirability distortion in computer-administered questionnaires, traditional questionnaires, and interviews. J. Appl. Psychol. 84, 754-775. doi: 10.1037/0021-9010.84.5.754

Sánchez-Prieto, J. C., Huang, F., Olmos-Migueláñez, S., García-Peñalvo, F. J., and Teo, T. (2019). Exploring the unknown: the effect of resistance to change and attachment on mobile adoption among secondary pre-eservice teachers. Br. J. Educ. Technol. 50, 2433-2449. doi: 10.1111/bjet.12822

Smith, E. E., Kahlke, R., and Judd, T. (2020). Not just digital natives: integrating technologies in professional education contexts. Aust. J. Educ. Technol. 36, 1-14. doi: $10.14742 /$ ajet.5689

Teo, T. (2009). Modelling technology acceptance in education: a study of pre-service teachers. Comput. Educ. 52, 302-312. doi: 10.1016/j.compedu.2008.08.006

Teo, T. (2013). An initial development and validation of a Digital Natives Assessment Scale (DNAS). Comput. Educ. 67, 51-57. doi: 10.1016/j.compedu.2013.02.012

Teo, T., and Huang, F. (2019). Investigating the influence of individually espoused cultural values on teachers' intentions to use educational technologies in Chinese universities. Interact. Learn. Environ. 27, 813-829. doi: $10.1080 / 10494820.2018 .1489856$

Teo, T., Huang, F., and Hoi, C. K. W. (2018). Explicating the influences that explain intention to use technology among English teachers in China. Interact. Learn. Environ. 26, 460-475. doi: 10.1080/10494820.2017.1341940

Teo, T., Kabakçi Yurdakul, I., and Ursavaş, Ö. F. (2016). Exploring the digital natives among pre-service teachers in Turkey: a cross-cultural validation of the digital native assessment scale. Interact. Learn. Environ. 24, 1231-1244. doi: 10.1080/10494820.2014.980275

Tran, T., Ho, M. T., Pham, T. H., Nguyen, M. H., Nguyen, K. L. P., Vuong, T. T., et al. (2020). How digital natives learn and thrive in the digital age: evidence from an emerging economy. Sustainability 12:3819. doi: 10.3390/su120 93819

Tsai, C. C., and Chai, C. S. (2012). The "third" -order barrier for technologyintegration instruction: implications for teacher education. Aust. J. Educ. Technol. 28, 1057-1060. doi: 10.14742/ajet.810

Venkatesh, V., and Bala, H. (2010). Technology acceptance model 3 and a research agenda on interventions. Decis. Sci. 39, 273-315. doi: 10.1111/j.1540-5915.2008.00192.x

Conflict of Interest: The authors declare that the research was conducted in the absence of any commercial or financial relationships that could be construed as a potential conflict of interest.

Publisher's Note: All claims expressed in this article are solely those of the authors and do not necessarily represent those of their affiliated organizations, or those of the publisher, the editors and the reviewers. Any product that may be evaluated in this article, or claim that may be made by its manufacturer, is not guaranteed or endorsed by the publisher.

Copyright $(2) 2021$ Zhao and Zhao. This is an open-access article distributed under the terms of the Creative Commons Attribution License (CC BY). The use, distribution or reproduction in other forums is permitted, provided the original author(s) and the copyright owner(s) are credited and that the original publication in this journal is cited, in accordance with accepted academic practice. No use, distribution or reproduction is permitted which does not comply with these terms. 